\title{
Photovoltaics: An Initiative Step towards Sustainable Technology
}

\author{
Ayesha Tooba Khan \\ (Department of Electrical Engineering, Zakir Husain College of Engineering \& Technology, Aligarh Muslim \\ University, India)
}

\begin{abstract}
The energy crisis is appearing as a grave problem the whole world is facing today. The challenge is to refine the renewable technologies to make them competitive with traditional energy sources. The paper mainly focuses on the recent trends in Photovoltaic Technology and photovoltaic market development in brief. Recent trends adopted in photovoltaics offers a key solution to deliver a sustainable, secure, reliable and long term supply of energy at efficient rate and affordable cost to the livelihood. The fast growing photovoltaic technology has currently acquired a position to lead the worldwide challenge and also has boosted the opportunities in industrial sector. The remarkable growth of the photovoltaic sector in recent years provides a clear justification for this publication. Also, the paper will give insight to the basics of photovoltaics.
\end{abstract}

Keywords - Cost and Performance, Energy Demand, Photovoltaic Technology, Renewable Energy Resources, Sustainable Development.

\section{INTRODUCTION}

The growing demand of energy and unjustified usage of traditional energy resources has led to a devastating imbalance in natural environment. The demand for energy is growing day by day but the corresponding supply is not rising with the same pace. Thus, energy crisis has become a key issue which must be addressed at extreme priority. The problem is not just to fulfil the present energy demands but also to establish a clean, safe, robust and efficient system for sustainable growth and development around the world. After exploration of various renewable energy resources like wind, hydroelectric, biomass and geothermal, a straight and right path has come into picture where the sun never sets. On average, the Earth receives about 12 MW of solar power. The challenge is to trap even a tiny fraction of this energy for sustainable future. The average annual growth rate of Global PV technology capacity is more than $40 \%$ since 2000 and it is expected to have significant potential for long term growth over the next decades. It is estimated that PV technology will provide $11 \%$ of global electricity production which is equal to $4500 \mathrm{TWh}$ per year corresponding to $3000 \mathrm{GW}$ of cumulative installed PV capacity and will avoid 2.3 gigatonnes of $\mathrm{CO}_{2}$ emissions per year ${ }^{[1]}$. Photovoltaics is becoming increasingly inexpensive which is making PV sector more lucrative. In the recent market, solar PV systems are more than 60\% cheaper than they were in the 1990s [2].

Looking at these aspects of photovoltaics, even the developing nations have taken the initiatives and are investing more in PV sector. The target is not just to install PV systems but also to reduce the manufacturing \& installation cost to make them profitable. The paper will review some of the advancements in technology which are most important in accounting for cost reduction and encouraging the performance of solar installations around the world and the position acquired by PV technology in global market.

\subsection{Introduction}

\section{Photovoltaic TeChNology}

Photovoltaics is the field of technology and research which directly converts solar energy into electrical energy using the devices that exhibits Photovoltaic Effect. In 1950s, the technology was developed for the space program to power the satellites. Later, in the early 1970s, it reached to a commercial status due to the evolving energy crisis.

Semiconductor device called a 'solar cell' can be considered as the heart of solar PV technology. The output power of the solar cell depends on the intensity of the incident radiation, its design and materials, and its temperature. Individual solar cells are electrically connected to each other and mounted in a frame which is called a PV module or 'panels'. Several modules are wired together to make an 'array'. They may either be connected in series or parallel to provide desirable voltage and current levels.

\subsection{Photovoltaic cell types}

The basic types of solar cells are wafer-based silicon cells and thin film solar cells. Wafer-based silicon cells are either cut from a single crystal rod or from a block made up of many crystals and accordingly called as mono-crystalline or multi-crystalline silicon solar cells. Wafer-based silicon cells are around 200 micron thick while thin film solar cells are approximately 1-2 micron thick and therefore less manufacturing cost is required in production of these cells. However, thin films indicate lower efficiencies than wafer-based silicon solar cells 
in the real world which means that more surface area and material is required for the installation to get a similar performance. Thus, Crystalline silicon has maintained at least $80 \%$ of the worldwide market production for nearly past 30 years ${ }^{[3]}$.

\subsection{PV Technologies}

There are two principal types of PV collection systems namely, Flat-plate and Concentrating. Flat-plate PV arrays can be mounted in a fixed orientation or allowed to track the movement of the sun. They respond to direct or diffuse sunlight. Concentrating PV systems employ less expensive materials such as lenses or mirrors to capture the incident solar radiations. Such systems usually employ at least 100 times concentration. But these concentrators can't focus diffuse light which is about 30\% of the solar radiation on a clear day. Moreover, due to high concentration of solar radiations, the temperature of the system rises and hence cell efficiencies and system stability is affected. For these reasons, Concentrating PV systems still account for less than $1 \%$ of the PV market $^{[3]}$.

\section{TECHNOLOGY STATUS AND TRENDS}

Major trends in PV technology mainly focus on improving performance as well as lowering manufacturing costs. After having mono crystalline, poly crystalline, amorphous thin-film and multi-junction cells, various innovative ideas have been evolved in recent years to make the technology more advanced.

\subsection{Nanostructure solar cell}

Princeton University researchers, led by an electrical engineer Stephen Chou, have found a simple and economic way to increase the efficiency of organic solar cells by 175 per cent. It is expected that this technology also would increase the efficiency of conventional inorganic solar cells, although the research is still in progress with inorganic devices. Their work has been published in the journal Optical Material Express Nov 2, $2012^{[4]}$.

The device uses a nanostructured 'sandwich' of metal and plastic which collects and traps light. The sandwich called Subwavelength Plasmonic Cavity, has extraordinary ability to trap the incident light and hence reduces the possibility of reflection. These cells reflects only about $4 \%$ of incident solar radiations. Using these devices, 52\% higher efficiency is achieved in converting light energy into electrical energy than a conventional solar cell. Fig.1 shown below depicts the trapping of radiations in conventional solar cell and advanced solar cell.
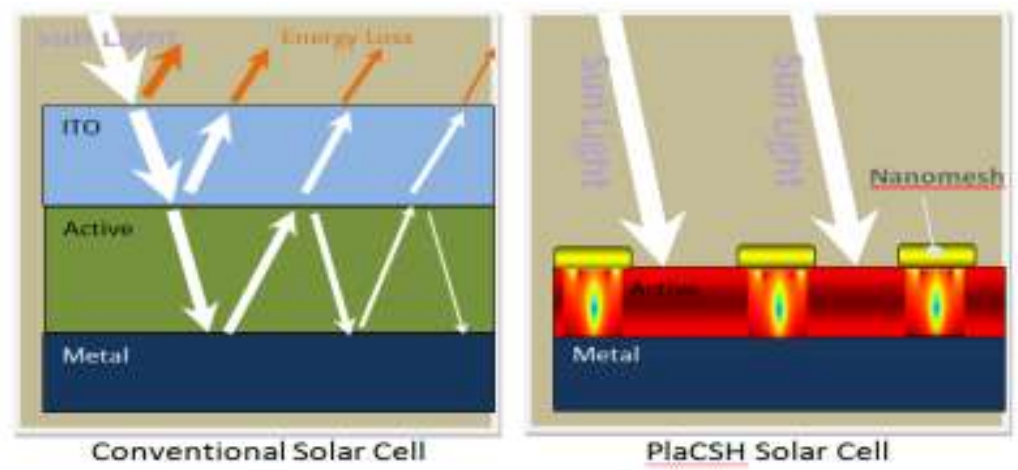

Figure 1:Trapping of light in Conventional Solar Cell and PlaCSH Solar Cell

The efficiency boosts to $81 \%$ when light strikes the cells at larger angle on cloudy days resulting to $175 \%$ of total increase. In place of Indium Tin Oxide (ITO), the most expensive part of conventional solar cells, the top layer uses a $30 \mathrm{~nm}$ thick mesh which is made up of metal, having apertures $172 \mathrm{~nm}$ in diameter and spacing $25 \mathrm{~nm}$ apart. This mesh is placed close to bottom layer of the same metal film used in conventional solar cells. A thin strip of semiconducting materials like silicon or Gallium arsenide (GaAs) is placed between the two metal

sheets.

The key features of the cell are the spacing of the mesh, the thickness of the sandwich, and the diameter of the holes which are all smaller than the wavelength of incident light. These subwavelength structures traps the light with almost no reflection. "It is like a black hole for light", said Chou ${ }^{[4]}$. The system has been given the name "Plasmonic Cavity with Subwavelength Hole Array (PlaCSH)" and it can be manufactured in wallpaper sized sheets using a process called Nanoimprints.

$\mathrm{PlaCSH}$ is extremely bendable while conventional solar cells are rigid. Apart from the higher efficiency, it can reduce the manufacturing cost and make the panels more flexible as it uses extremely thin layer of semiconducting material. "The team plans further experiments and expects to increase the efficiency of the PlaCSH system as they refine the technology", Chou said ${ }^{[4]}$. 


\subsection{All Carbon Solar Cell}

Stanford University Researchers, led by Zhenan Bao, professor at Stanford, have developed a solar cell made entirely of Carbon which is considering as an alternative to the expensive materials used in PV devices. For example, ITO used in conventional solar cell is more expensive because of its high demand in PV market and scarcity of Indium while Carbon is a low cost abundant material.

The flexible Carbon solar cell consists of a photoactive layer, sandwiched between the two electrodes. The ITO and Silver used in conventional electrodes is replaced with graphene, 1 atom thick Carbon sheet and single-walled Carbon nanotubes which are 10,000 times narrower than a human hair. These carbon nanotubes have extraordinary light absorbing tendency and electrical conductivity and they can be dispersed in water or organic solvent with the help of surfactants thereby can be used in coating processes which is a low cost manufacturing technique. "Perhaps in the future we can look at alternative markets where flexible carbon solar cells are coated on the surface of buildings, on windows or on cars to generate electricity" Bao said ${ }^{[5]}$. The active layer is made up of carbon nanotubes, acting as donor layer and bucky balls, soccer ball shaped carbon molecules which are $1 \mathrm{~nm}$ in diameter and serves as electron acceptor. The device can perform under extreme conditions as it consists of carbon materials which have excellent mechanical properties and they remain stable at the temperature around 1,100 degrees Fahrenheit. These Carbon cells primarily absorb near infrared wavelengths of light which effects the efficiency of the cell and it appears as the drawback for this low cost \& robust technique. Looking at the ability of the device to perform under extreme conditions, a compromise can be made with the efficiency. Although, the Stanford Team is performing experiments with carbon nano materials to improve efficiency so that it can absorb more light in a broader range of wavelengths ${ }^{[5]}$.

\subsection{Colloidal Quantum Dot Solar Cell}

A team of researchers from University of Toronto ( $\mathrm{U} \& \mathrm{~T}$ ), Canada and King Abdullah University of Science \& Technology (KAUST),Saudi Arabia, under the supervision of professor Ted Sargent of U \& T have introduced the most efficient Colloidal Quantum Dot (CQD) solar cell. Their work has been published in Nature Materials ${ }^{[6]}$.

Quantum dots are basically the semiconducting materials whose size is of the order of nanometre and are compatible to spray on to flexible surfaces. The energy gap of CQDs can be varied over a wide range of energies just by modifying their size which enables them to absorb light from visible as well as invisible region of the entire spectrum. This technique has low manufacturing cost, greater durability and can be created quickly as compared to conventional solar cells. Earlier, the work was carried out with organic molecules which resulted in high surface area to volume ratio thereby affecting the cell efficiency by creating the 'traps' for electrons and providing them with the recombination time. But, now it has been replaced with inorganic ligands to bind the quantum dots together with less space between them and to limit the number of 'traps' for electrons thereby improving surface quality. "By introducing small chlorine atoms immediately after synthesizing the dots, we're able to patch the previously unreachable nooks and crannies that lead to electron traps," said Alex, lead coauthor ${ }^{[6]}$. With this close packing combination and charge trap elimination, the device has been modified to provide a world-record efficiency of $7.0 \%$. Researches are still going on for further reducing the electron traps and introducing different size of quantum dots to make the cell highly efficient. A technology licensing agreement has been signed by KAUST and U\&T to make the use of technology popular on commercial scale. "Our world urgently needs innovative, cost-effective ways to convert the sun's abundant energy into usable electricity. This work shows that the abundant materials interfaces inside colloidal quantum dots can be mastered in a robust manner, proving that low cost and steadily-improving efficiencies can be combined." Said Professor Sargent ${ }^{[6]}$.

\section{Photovoltaic MARKet DeVelopment}

As a result of improving power conversion efficiencies, development of low cost solar fabrication processes and huge increase in cell production volume, significant cost reductions are expected to continue which will help the PV market development. Currently, photovoltaics has become the third most important renewable energy source in terms of globally installed capacity after hydro and wind power ${ }^{[7]}$.

\subsection{Photovoltaics Growth around the World}

From the Fig. shown below, it can be clearly seen that the growth of PV sector is remarkable from 2009-2012. The annual installed amount of PV system is expressed in GW and is represented by the bars shown in Fig. The approximate growth rate was around 70\% per year during the session 2007-2012. There was a heavy blow of 172\% in PV market during 2009 and 2010. At the end of 2011, there was a total of about $62 \mathrm{GW}$ of installed PV systems around the globe. However, in 2011 the growth was just satisfactory.

With increasing interest in energy market, $\mathrm{PV}$ technology is growing at a rapid rate around the whole world. 


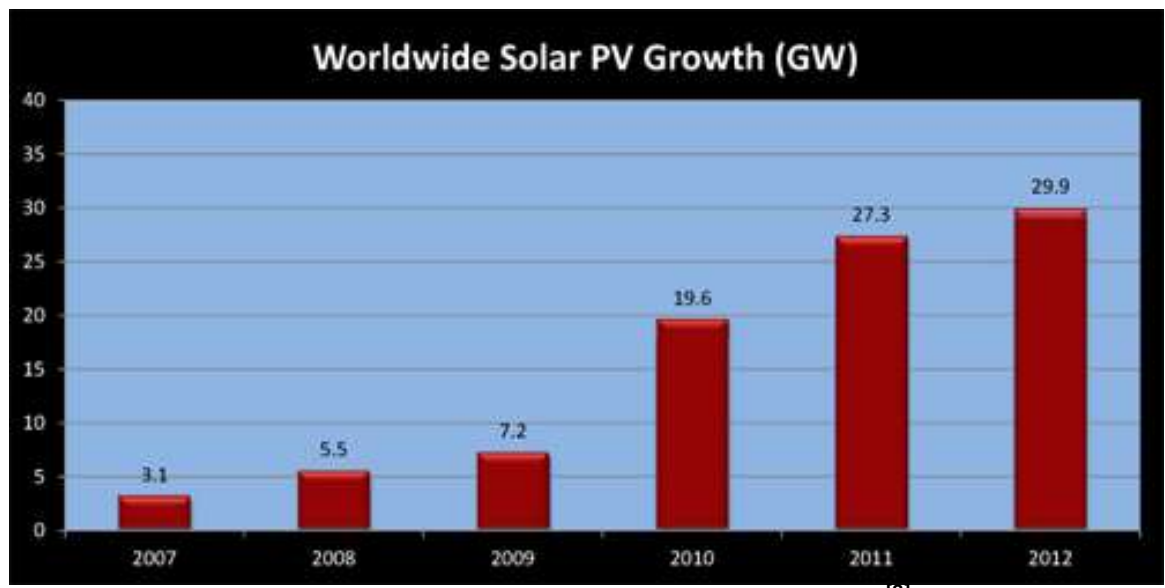

Figure2: PV Solar Growth in $\mathrm{GW}^{[8]}$

\subsection{PV Installations in various Nations}

The Table below shows that Germany is currently leading the global PV market and by the year 2020, Germany has set the aim to replace all its nuclear power by renewable energy resources. The year 2011 was the blooming year for Italy as there was the whopping growth of PV installations in the country ${ }^{[8]}$. It is estimated that $40 \%$ of the projects bought are located in Germany while $35 \%$ are in Italy and the remaining $25 \%$ are located internationally. Apart from the well developed nations like Germany, Italy, United States, France, Japan and Australia, even the developing nations like India and China are investing more in PV sector for sustainable growth and development. China produces more than half the world's supply of solar modules so it is obvious that government of China will also focus on local installations. In India, Jawahar Lal Nehru National Solar Mission is targeting $20 \mathrm{GW}$ of generation capacity by $2022^{[9]}$. In an article written by Raj Prabhu in Mercom Capital Group, it is claimed that Gujarat state has completed with $655 \mathrm{MW}$ of its $968.5 \mathrm{MW}^{\text {goal }}{ }^{[9]}$. States like Karnataka, Orissa and Tamil Nadu are also accounting for PV installations to boost solar power production in India.

Table 1: PV Solar Installations By Country ${ }^{[8]}$

\begin{tabular}{|l|c|c|c|}
\hline Country & $\mathbf{2 0 1 0}$ & $\mathbf{2 0 1 1}$ & $\mathbf{2 0 1 2}$ \\
\hline Germany & 7.5 & 7.5 & 5.5 \\
\hline Italy & 4.3 & 6.3 & 4.5 \\
\hline United States & 0.9 & 1.9 & 3.8 \\
\hline Japan & 0.9 & 1.3 & 2.5 \\
\hline France & 0.6 & 1.8 & 1.5 \\
\hline China & 0.6 & 2.8 & 4.5 \\
\hline Australia & 0.4 & 0.8 & 1.0 \\
\hline India & 0.1 & 0.6 & 1.5 \\
\hline ROTW & 4.3 & 4.3 & 5.1 \\
\hline Total Market & 19.6 & 27.3 & 29.9 \\
\hline
\end{tabular}

\section{CONCLUSION}

Worldwide PV system installation has been growing at a rapid rate in past few years. A key goal is to drive down the cost of production by introducing extraordinary advancements in PV technology which can make Photovoltaics more delicious. And no doubt, we have taken the initiative towards the destiny. The paper has reviewed the latest technologies that should be adopted on commercial scale very soon to boost the solar power production as we are surrounded with issues like Global Warming and Energy Crisis. Photovoltaic sector can be made more productive \& competitive with these stronger efforts \& technological innovations. The current status of PV sector in various countries has been discussed in brief which can give an approximate idea about the development and economic status of the countries.

Though, it is uncertain to predict the extent of future growth of this dynamic and fast growing technology just by looking at the current status it is expected that advanced PV technology will provide the path to go 'green' with sustainability and affordability. 


\section{REFERENCES}

[1] Technology Roadmap- Solar Photovoltaic Energy,IEA

[2] Report, Photovoltaic Solar Energy Development and current research, European Commission 2009

[3] Solar Photovoltaics: Status, Costs and Trends, EPRI, December 2009

[4] Princeton University, Engineering School.’Tiny Structure Gives Big Boost to Solar Power." Science Daily, 6Dec..2012. Web.13Dec.2012

[5] “Scientists Build the First All-Carbon Solar Cell.” Science Daily, Stanford University.31Oct.2012. Web.12 Jan.2013

[6] University of Toronto Faculty of Applied Science \& Engineering ." Record efficiency for next-generation solar cells. ScienceDaily. 29Jul.2012. Web 31Dec.2012

[7] Photovoltiacs- wikipedia, [accessed 16Dec. 2012]

[8] Raj Prabhu,'Will india join the 'gigawatt club' this year?", Mercom Capital Group,[www.mercom capital.com/india-newsanalysis][accessed 02Jan.2013]

[9] Solar cell central By: Four Peak technologies, Inc. Scottsdale, AZ, Solar Markets [solar cell central.com/markets_page.html],[accessed 16Jan.2013] 